\title{
Endovascular Treatment of Hepatic Artery Pseudoaneurysm secondary to an Erosion and Liver Block of Perforated Peptic Ulcer
}

\author{
Tratamento Endovascular de Pseudoaneurisma de Artéria Hepática \\ Secundário à Erosão e Bloqueio Hepático de Úlcera Péptica Perfurada
}

Ricardo de Alvarenga Yoshida', Paulo Roberto Bahur Vieira², Winston Bonetti Yoshida ${ }^{3}$,

Marcone Lima Sobreira ${ }^{4}$, Rodrigo Gibin Jaldin ${ }^{5}$ Rodolfo Lellis Zuppardo², Regina Moura ${ }^{4}$

\section{INTRODUCTION}

The major complications of peptic ulcers are bleeding and perforation ${ }^{1}$. The risk factors for these complications are: previous peptic ulcer or gastrointestinal bleeding; old age; use of nonsteroidal anti-inflammatory drugs (NSAIDs); use of anticlotting or antiplatelet agents; severe comorbidities; high doses of aspirin; and infection by Helicobacter pylori ${ }^{2}$. In the case of perforation, the best treatment is suture, followed by antisecretory therapy and eradication of $H$. pylori infection, when present ${ }^{1}$.

Perforated peptic ulcer may be blocked by adjacent visceral tissues or organs. Possible erosions may expose them to the action of gastrointestinal enzymes that may, occasionally, affect the wall of arteries and veins. Reports in the literature describe cases of involvement of the cystic artery ${ }^{3,4}$ and the hepatic artery ${ }^{5}$.

This study describes a case of pseudoaneurysm of the hepatic artery resulting from a complication of peptic ulcer perforation. No similar case was found in the literature.

\section{PART I - CLINICAL CASE}

A 41-year-old woman presented 3 months after surgery to treat a perforated peptic ulcer by suturing. Surgery records indicated that the gastric ulcer had been blocked by the gall bladder, which had to be removed during the operation. Thirty days after the operation, the patient underwent another surgery due to another perforated gastric ulcer and had to undergo another procedure been necessary partial gastrectomy. At this second operation, the gastric ulcer had been blocked by the gall bladder liver bed; during the attempt to partially remove the stomach, a pulsatile dilatation was noted at this site. The decision at the time was to stop the procedure and conduct an elective investigation of that lesion. Immediately after operation, the patient had melena. Computed tomography angiography (AngioCT) revealed aneurysmal dilatation suggestive of pseudoaneurysm of the proper hepatic artery, without rupture, but with material inside it, which was compatible with a recent thrombus (Figure 1).

The treatment option in these cases is open surgery for proximal and distal ligation. However, embolization of pseudoaneurysm is a less invasive option, particularly for patients with comorbidities or complications following the first surgery.

We chose an endovascular approach because, in addition to the conditions described above, technical difficulties might be faced using the conventional approach to the proper hepatic artery in a hostile abdomen.

A right femoral access was used for aortography, which showed that the celiac trunk had no wall irregularities or calcifications. Therefore, selective catheterization of the celiac trunk and superselective catheterization of the hepatic artery were performed. Angiography revealed a pseudoaneurysm of the proper hepatic artery (Figure 2a). A 0.035 ",

\footnotetext{
'Angiovalle, São José dos Campos, SP; Universidade Estadual Paulista - UNESP, Faculdade de Medicina de Botucatu - FMB, Department of Surgery and Orthopedics, Botucatu, SP, Brazil.

${ }^{2}$ Angiovalle, São José dos Campos, SP, Brazil.

${ }^{3}$ Universidade Estadual Paulista - UNESP, Faculdade de Medicina de Botucatu - FMB, Botucatu, SP, Brazil.

${ }^{4}$ Universidade Estadual Paulista - UNESP, Faculdade de Medicina de Botucatu - FMB, Botucatu, SP, Brazi

Enniversidade Estadual Paulista - UNESP, Faculdade de Medicina de Botucatu - FMB, Botucatu, SP, Brazil.

Conflicts of interest: No conflicts of interest declared concerning the publication of this article.

Financial support: None.

Submitted: 26.09.12. Accepted: 19.12.12
}

The study was carried out at Centro Cardiovascular Avançado do Hospital Vivalle - São José Dos Campos - SP. 


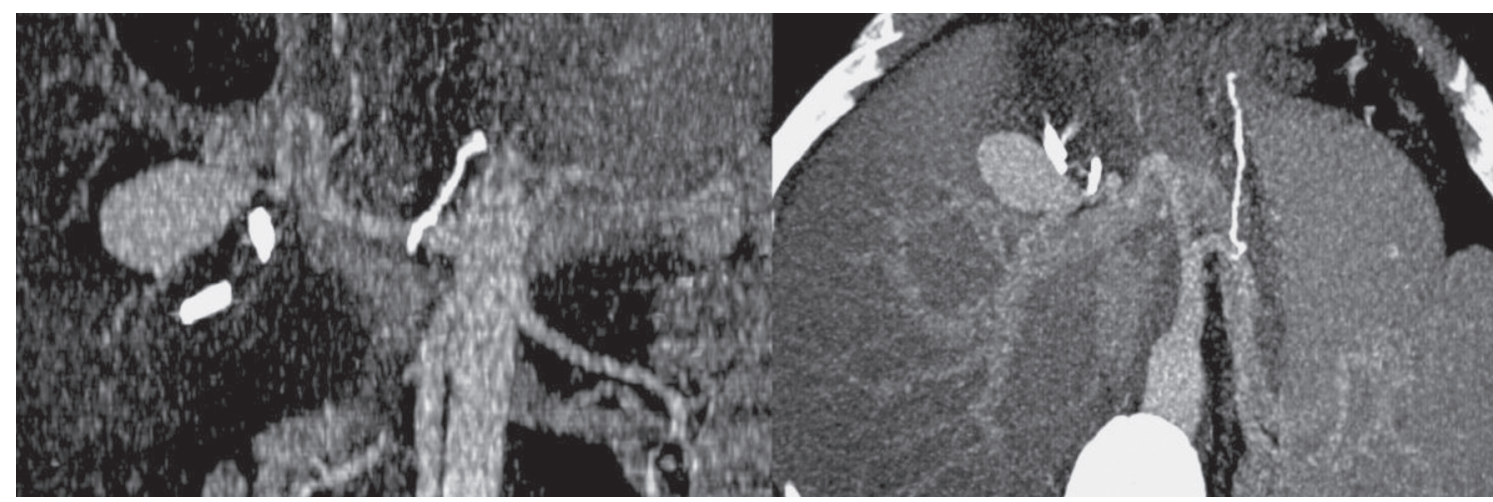

Figure 1. AngioCT: aneurysmal dilatation suggestive of pseudoaneurysm in proper hepatic artery.

260-cm long stiff hydrophilic guidewire was then kept in place for the placement of the 11-cm valved introducer with a 45-cm RDC catheter to improve support for endovascular navigation. After that, the stiff $0.035 " 260-\mathrm{cm}$ hydrophilic guidewire was replaced with a $2.8-\mathrm{mm}$ microcatheter and a 0.014 " $180-\mathrm{cm}$ guidewire for extra support. After that, 6-mm platinum coils (AZUR ${ }^{\mathrm{TM}}$ Peripheral HydroCoil Embolization System, Terumo Interventional Systems $^{\mathrm{R}}$, Somerset, NJ), available at that time, were deployed in the aneurysm sac to achieve partial thrombosis of the pseudoaneurysm (Figure 2b). However, the coils were knowingly small for the large size of the aneurysm sac. Therefore, 4-mm platinum coils (AZUR ${ }^{\mathrm{TM}}$ Peripheral HydroCoil Embolization System, Terumo Interventional Systems ${ }^{\mathrm{R}}$, Somerset, $N J$ ) were used to occlude the neck of the aneurysm (Figure 2c). Control AngioCT showed the complete occlusion of the pseudoaneurysm and preserved flow to the hepatic artery (Figure $2 \mathrm{~d}$ ).

The patient was kept in the intensive care unit (ICU) for 24 hours and 2 more days in a hospitalization ward for observation. She had no bleeding at discharge. Control AngioCT at 3 months showed full exclusion of the pseudoaneurysm and preserved blood flow to the hepatic artery (Figure 3).

\section{DISCUSSION}

Intra-hepatic pseudoaneurysms may occur as a consequence of blunt or penetrating abdominal trauma. Incidence has increased along the last two decades because of iatrogenic pseudoaneurysms resulting from the growing number of invasive procedures to treat diseases of the hepatobiliary tract, such as endovascular interventions, liver biopsies, percutaneous biliary drainage, colecystectomies, and other gall bladder operations, which are responsible for up to $50 \%$ of the cases of pseudoaneurysms
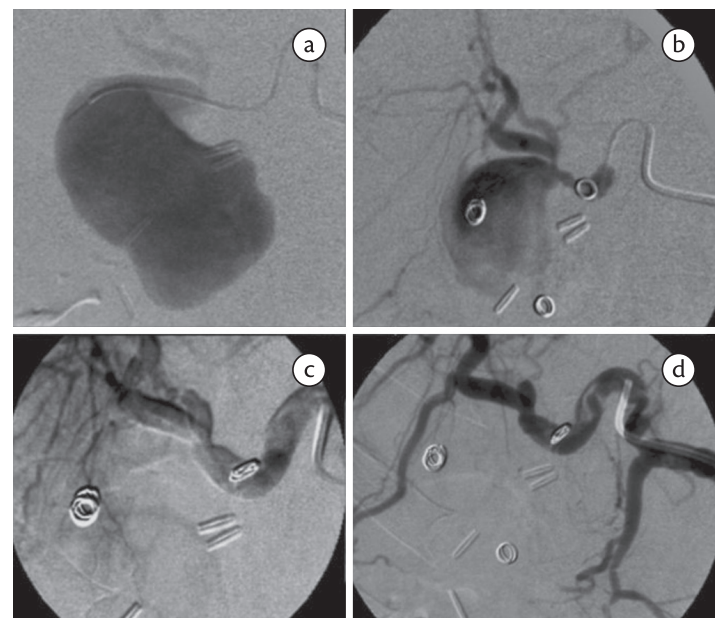

Figure 2. a) transoperative Angiogram: pseudoaneurysm of hepatic artery proper; b)implant of platinum coils to provoque partial thrombosis of pseudoaneurysm; c) closure of aneurysm sac neck using platinum coils, which promoted full thrombosis of pseudoaneurysm; d) control angiography: complete occlusion of pseudoaneurysm and preserved flow to hepatic artery.

in this anatomic site ${ }^{6-8}$. Periarterial inflammation, which may occur after inflammation of perihepatic intra-abdominal organs, such as cholecystitis or pancreatitis, is an unusual cause of aneurysms of the hepatic artery ${ }^{9}$. In review of the literature did not identify any similar case, in which a perforated peptic ulcer and liver block eventually eroded the wall of the hepatic artery and led to the formation of the pseudoaneurysm.

Aneurysms and pseudoaneurysms of hepatic arteries may be treated by open surgery (reconstruction or ligation) or endovascular repair. In general, open surgery is a more invasive procedure, poses some difficulties to access and, consequently, greater morbidity and mortality, which may result in up to $21 \%$ perioperative mortality ${ }^{10,11}$. In the case 


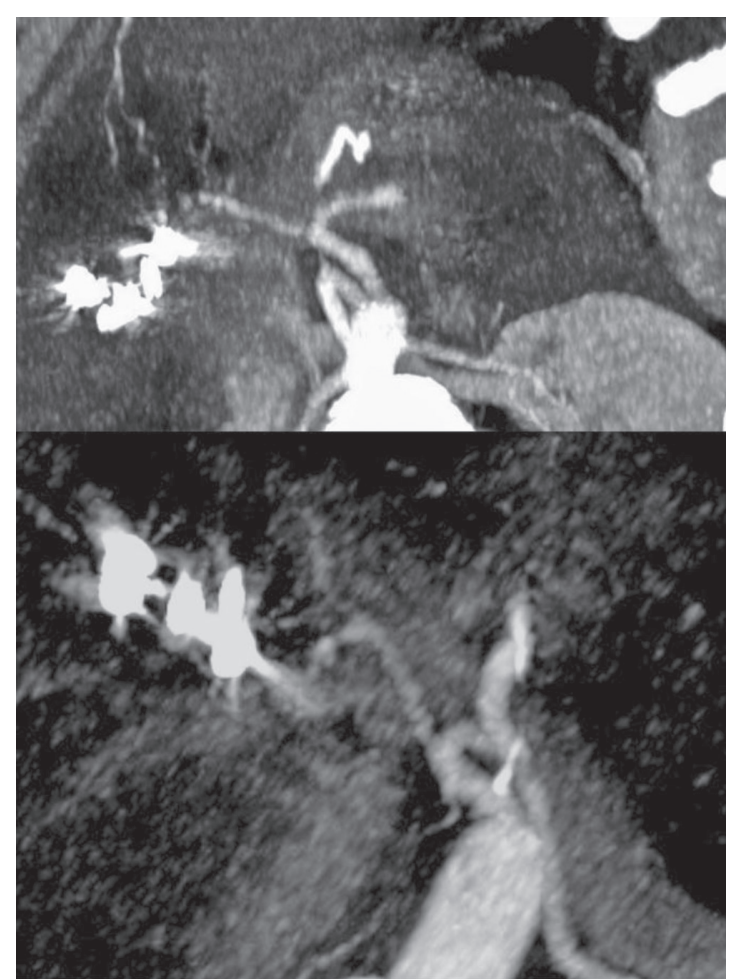

Figure 3. Control AngioCT at 3 months: full pseudoaneurysm exclusion and preserved blood flow to hepatic artery.

reported here, conventional surgery would require intra-hepatic access, which is particularly difficult. Moreover, the patient had a hostile abdomen due to two previous abdominal surgeries. The options for endovascular repair are: therapeutic embolization ${ }^{12}$; transhepatic embolization ${ }^{13}$; stent placement; ultrasound-guided percutaneous thrombin injection ${ }^{14}$; and coated stents ${ }^{15,16}$.

The use of free or coated stents is indicated for major arteries when vascular occlusion may pose the risk of great tissue loss downstream from the site affected. However, anatomy must be favorable and include adequate vessel caliber and tortuosity and arterial walls that are not friable.

In this case, we chose coil embolization because the pseudoaneurysm was well-delimited in the proper hepatic artery, with a single neck, and without distal repercussions of its occlusion. The use of adequate material is important. In this case, the very small coils used in an emergency situation led to partial thrombosis, which was the purpose, but were not enough for its full exclusion. The deployment of coils, although very small, inside the aneurysm to produce as much thrombosis as possible, associated with the occlusion of its neck, was a satisfactory solution for the treatment of the pseudoaneurysm, considering that it was an emergency case and using the material available at that time. Transhepatic embolization should be used only for cases in which conventional access (via femoral, brachial or axillary artery) is complicated, or when the vessel to be treated is not accessible from trunk arteries ${ }^{13}$.

Therefore, the main advantage of therapeutic embolization is the production of focal ischemia and thrombosis in the organ affected, with the purpose of treating the disease and preserving the organ ${ }^{17}$. Limitations and potential sources of complications of embolization are associated with ischemia of tissues adjacent to the lesion or inadvertent embolization of other organs ${ }^{18}$.

In conclusion, this report described a rare, urgent situation treated with embolization of the pseudoaneurysm of the proper hepatic artery. This technique was successful due to pseudoaneurysm exclusion, and the patient was spared a critical condition, as the procedure used was not too invasive.

\section{REFERENCES}

1. Tomtitchong $P$, Siribumrungwong B, Vilaichone RK, Kasetsuwan P, Matsukura N, Chaiyakunapruk N. Systematic review and meta-analysis: Helicobacter pylori eradication therapy after simple closure of perforated duodenal ulcer. Helicobacter. 2012;17:148-52. PMid:22404446. http://dx.doi. org/10.1111/j.1523-5378.2011.00928.x

2. Valkhoff VE, Sturkenboom MC, Kuipers EJ. Risk factors for gastrointestinal bleeding associated with low-dose aspirin. Best Pract Res Clin Gastroenterol. 2012;26:125-40. PMid:22542151. http://dx.doi.org/10.1016/j.bpg.2012.01.011

3. Ring SM, Beranbaum ER, Madayag MA, Leahy WF. Peptic erosion of the cystic artery. An unusual etiology of spontaneous gastrointestinal hemorrhage. Angiology. 1972;23:554-7. PMid:4538723. http://dx.doi.org/10.1177/000331977202300907

4. Cooper SG, Morse SS, Strauss EB. Peptic erosion of the cystic artery with massive duodenal hemorrhage: therapeutic embolization. Cardiovasc Intervent Radiol. 1988;11:278-80. PMid:3145141. http://dx.doi.org/10.1007/BF02577035

5. Case TC. Massive postoperative hemorrhage from hepatic artery erosion. J Am Geriatr Soc. 1976;24:555-7. PMid:1086860.

6. Raymundo SRO, Hussain KMK, Godoy MF, Silva AAM, Nagato LC. Pseudo-aneurisma de artéria hepática. Cir Vasc Angiol. 2000;16:136-144.

7. Belli AM, Markose G, Morgan R. The role of interventional radiology in the management of abdominal visceral artery aneurysms. Cardiovasc. Intervent. Radiol. 2012;35:234-43. PMid:21674280. http://dx.doi.org/10.1007/s00270-011-0201-3

8. Jana M, Gamanagatti S, Mukund A, et al. Endovascular management in abdominal visceral arterial aneurysms: A pictorial essay. World J Radiol. 2011;3:182-7. PMid:21860714 PMCid:3158896. http://dx.doi.org/10.4329/wjr.v3.i7.182

9. Harvey J, Dardik H, Impeduglia T, Woo D, DeBernardis F. Endovascular management of hepatic artery pseudoaneurysm hemorrhage complicating pancreaticoduodenectomy. J Vasc Surg. 2006;43:613-7. PMid:16520182. http://dx.doi.org/10.1016/j. jvs.2005.11.031 
10. Chiesa R, Astore D, Guzzo G, et al. Visceral artery aneurysms. An Vasc Surg. 2005;19:42-48. PMid:15714366. http://dx.doi. org/10.1007/s10016-004-0150-2

11. Chiesa R, Astore D, Castellano R, et al. Management of visceral artery aneurysms. J Vasc Bras. 2005:27-34.

12. Sidhu MK, Shaw DW, Daly CP, Waldhausen JH, Coldwell D. Post-traumatic hepatic pseudoaneurysms in children. Pediatr Radiol. 1999;29:46-52. PMid:9880616. http://dx.doi.org/10.1007/ s002470050532

13. Marcheix B, Dambrin C, Cron C, et al. [Transhepatic percutaneous embolisation of a post-traumatic pseudoaneurysm of hepatic artery]. Ann Chir. 2004;129:603-6. PMid:15581823. http://dx.doi. org/10.1016/j.anchir.2004.10.003

14. Barge JU, Lopera JE. Vascular complications of pancreatitis: role of interventional therapy. Korean J Radiol. 2012;13(Suppl 1):S4555. PMid:22563287 PMCid:3341460. http://dx.doi.org/10.3348/ kjr.2012.13.S1.S45

15. Flum AS, Geiger JD, Gemmete JJ, Williams DM, Teitelbaum DH. Management of a traumatic hepatic artery pseudoaneurysm and arterioportal fistula with a combination of a stent graft and coil embolization using flow control with balloon remodeling. J Pediatr Surg. 2009;44:e31-6. PMid:19853737. http://dx.doi. org/10.1016/j.jpedsurg.2009.07.036

16. Alvi AR, Bibi S, Zia UR R, Khan S. Non-traumatic right hepatic artery pseudoaneurysm: an unusual cause of hemobilia and obstructive jaundice. J Coll Physicians Surg Pak. 2009;19:800-2. PMid:20042163.

17. Feitosa A. Plugs, Molas e Micropartículas para Embolização. In: Lobato A, editor. Cirurgia Endovascular. 2. ed. São Paulo: ICVE; 2010. v. 1, p. 393-426.
18. Souza VC, Orlando JL. Embolização Transcateter no Tratamento de Lesões Vasculares. In: Maffei F, Lastoria S, Yoshida W, Gianini $M$, Moura R, editores. Doenças Vasculares Periféricas. 4. ed. Rio de Janeiro: Guanabara-Koogan; 2008. v. 1, p. 1007-1020.

$$
\begin{array}{r}
\text { Correspondence } \\
\text { Ricardo de Alvarenga Yoshida } \\
\text { FMB - UNESP } \\
\text { CEP 18618-970 - Botucatu (SP), Brazil } \\
\text { Fone: (14) 3811-6269 } \\
\text { E-mail: ricardoyoshida@gmail.com } \\
\text { Author information }
\end{array}
$$

RAY is a vascular and endovascular surgeon at Angiovalle; Collaborating professor in the discipline of Vascular and Endovascular Surgery at Faculdade de Medicina de Botucatu (FMB), Universidade Estadual Paulista (UNESP); PhD, Department of Surgery and Orthopedics, FMB (UNESP)

PRBV, RLZ are vascular and endovascular surgeons at Angiovalle. WBY is full professor and chief of the Service of Vascular and Endovascular Surgery at FMB (UNESP)

MLS, RM are assistant professors of the Service of Vascular and Endovascular Surgery at FMB (UNESP)

$R G$ ) is assistant physician of the Service of Vascular and Endovascular Surgery at FMB (UNESP)

Author contributions Conception and design: RAY, WBY Analysis and interpretation: RAY, WBY Data collection: RAY, WBY, PRBV, MLS, RG), RLZ, RM Writing the article: RAY, WBY Critical revision of the article: RAY, WBY Final approval of the article*: RAY, WBY, PRBV, MLS, RGJ, RLZ, RM Statistical analysis: N/A Overall responsibility: RAY ${ }^{*}$ All authors have read and approved the final version submitted to I Vasc Bras. 